\title{
Application Use of Augmented Reality in the Educational Process
}

\author{
Monika Töröková, Darina Dupláková, Jozef Török, Ján Duplák \\ Technical University of Kosice, Faculty of technologies with a seat in Presov, \\ Bayerova 1, 08001 Prešov, Slovakia
}

\begin{abstract}
Educational tools for computer modelling with the implementation of augmented reality elements have an irreplaceable place in the period of the digital revolution of Industry 4.0. The integration of augmented reality into the educational process in the field of computer modelling, in this paper, consists in the creation of technical documentation of the wheel suspension part and the subsequent creation of an application for the visualization of this model in the real environment.
\end{abstract}

Keywords - Augmented reality, education process, computer modelling

\section{Introduction}

The application of augmented reality techniques and technologies is one of the modern tools which supports development not only in the field of mechanical engineering. The requirements for a radical rationalization of the development process and a reduction in the time of introduction of innovations lead to the rapid application of new methods and technologies.

DOI: $10.18421 /$ SAR41-03

https://doi.org/10.18421/SAR41-03

Corresponding author: Monika Töröková,

Technical University of Kosice, Faculty of Manufacturing

Technologies with a seat Presov, Bayerova 1, 08001

Presov, Slovakia.

Email: monika.torokova@tuke.sk

Received: 16 February 2021.

Revised: 09 March 2021.

Accepted: 17 March 2021.

Published: 22 March 2021.

(c) BY-NC-ND (C) 2021 Monika Töröková et al; published by UIKTEN. This work is licensed under the Creative Commons Attribution-NonCommercial-NoDerivs 3.0 License.

The article is published with Open Access at www.sarjournal.com
Studies of new engineering projects show that the current time requires the use of new approaches in all stages of the product life cycle, not only in the design part but also, for example, in the production, assembly and service phases [9], [10]. The current development of technology, especially industrial production, is dynamic and complex. Mechanical engineering is influenced by the requirements for fast production and is mostly the first which directly implements new technologies. Continuous improvements in production processes necessarily require modernization of the education process itself. [1]

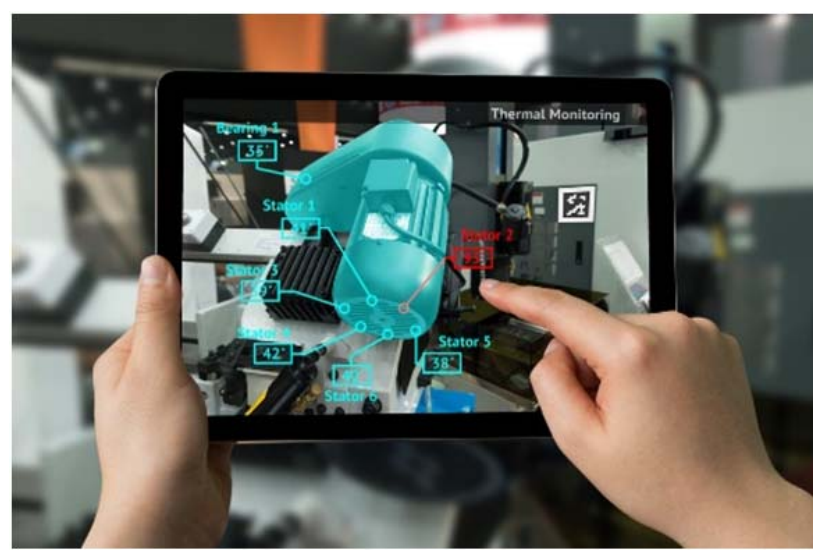

Figure 1. Demonstration of the use of augmented reality in the industry [5]

Augmented Reality, also known as AR is currently one of the largest and the most popular technological trends, as it offers the unification of the real world with the virtual. Under certain conditions, by implementing digital elements in the real world, it is possible to create an enriched reality, where the individual can control both virtual content and the real environment. [4] It can be various basic sensory elements of textual and graphical nature, GPS data that responds in real-time to changes in the user's environment, or he acts directly by selecting instructions on the machine. This generated content can be visible via smartphones, tablets or special AR glasses. 


\section{Possibilities of Using AR in the Educational Process}

Augmented reality technology in education has an important role to play, which is not limited to one age category. Primary schools, high schools, colleges and universities around the world are moving from traditional to more advanced methods. Paper books and textbooks are gradually being supplemented by electronic books. Wooden and plastic boards, chalk and pen are being replaced by displays and tablets. [6] As part of the educational process, during which it is possible to encounter quite often the issue of different levels of spatial vision of stakeholders, we often find ourselves in a situation where ordinary 2D technical documentation is not enough, and often slows down or complicates the understanding process.

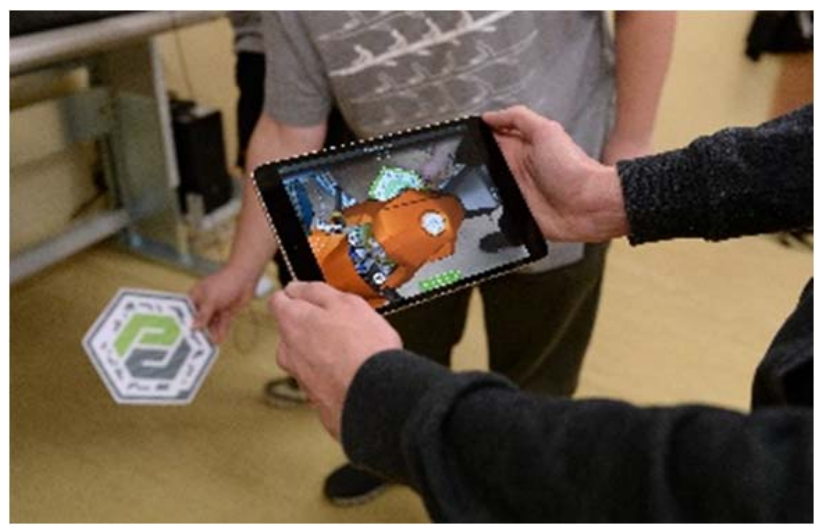

Figure 2. Demonstration of AR visualization in the educational process

For this purpose, a demonstration of the spatial model and subsequent 2D documentation in the form of assembly drawings was created, to which a marker was added to enable the display of a spatial object within the augmented reality environment. By creating three-dimensional models, assemblies and entire production sections with the implementation of elements of augmented reality, the created system aims, in particular, to improve the imagination and spatial vision of students who come from nontechnical schools.

Advantages of using augmented reality in the educational process:

- Eye-catching presentations - by integrating augmented reality into presentations, it is possible to gain more audience attention than with classic presentations, which keeps information in memory longer due to practical and dynamic demonstrations [2].

- Interactive teaching - audience participation in teaching. Students can access augmented reality models directly on their mobile devices with the use of different applications. By perceiving augmented reality, students can better understand the issue. In this way, students memorize more of the lectures, thanks to the application of provided visualization techniques.

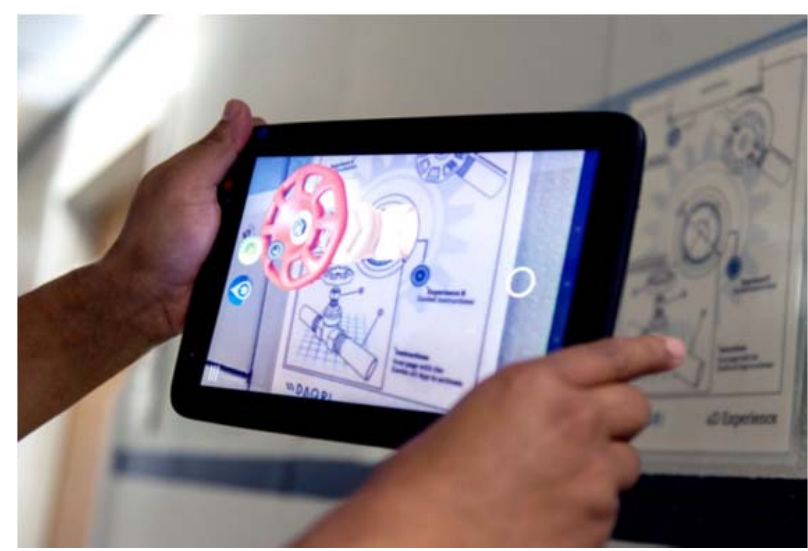

Figure 3. Demonstration of interactive teaching [5]

- Portable and inexpensive educational materials physical models, prototypes and detailed illustrations are often extremely expensive. Schools do not always have sufficient funding to provide teaching materials and aids of sufficient quality and quantity. By transferring teaching materials and aids into an illustrative digital form and implementing them in an augmented reality environment, educational institutions can save a large amount of money [8].

- Once created, digital content can be easily shared across the enterprise as well as learning centres [3].

- Promoting curiosity - incorporating augmented reality into the educational process brings enthusiasm to students. They are growing up in the era of digital technologies are increasingly confronted with augmented reality, which can inspire them and help build the effort to create their digital content in them [11].

\section{Processing Digital Content on a Specific Software Platform}

The introduction of augmented reality means into the educational process consists in the creation of 3D models for available visualization devices. The following illustrative example is a wheel suspension assembly, which is made in the Creo 6.0 software environment. The individual parts were modelled and then assembled in the Assembly module. By using the appropriate links and constraints, the correct simulation of the assembly behaviour is guaranteed. Other compatible software platforms were used to create the AR application. 


\subsection{PTC Creo}

PTC Creo is a comprehensive CAD / CAM / CAE software suitable for creating innovations and increasing quality using unique features designed by PTC [9]. When designed in this software, accurate digital models of the highest quality are quickly generated, regardless of geometric complexity. The final visualization with AR elements includes the wheel suspension part assembly created in PTC Creo Parametric 6.0.

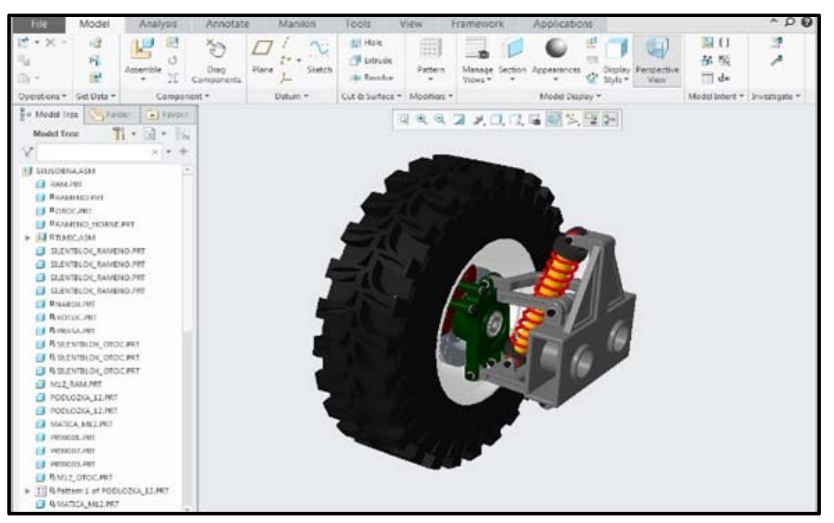

Figure 4. Assembly in the program PTC Creo

\subsection{Creo Illustrate}

The animations are created by the Creo Illustrate program, which is characterized by the generation of dynamic spatial transitions and technical illustrations from CAD data of the Creo software [7]. The tools of this software allow the authors of the accompanying documentation and service technicians to use 3D design data to create operating instructions, service procedures, spare parts catalogues or in this case to generate 3D animations for interactive technical publications. The designed assembly from the Creo software environment was then exported to the Creo Illustrate program where further work was done via the Sequence tab.

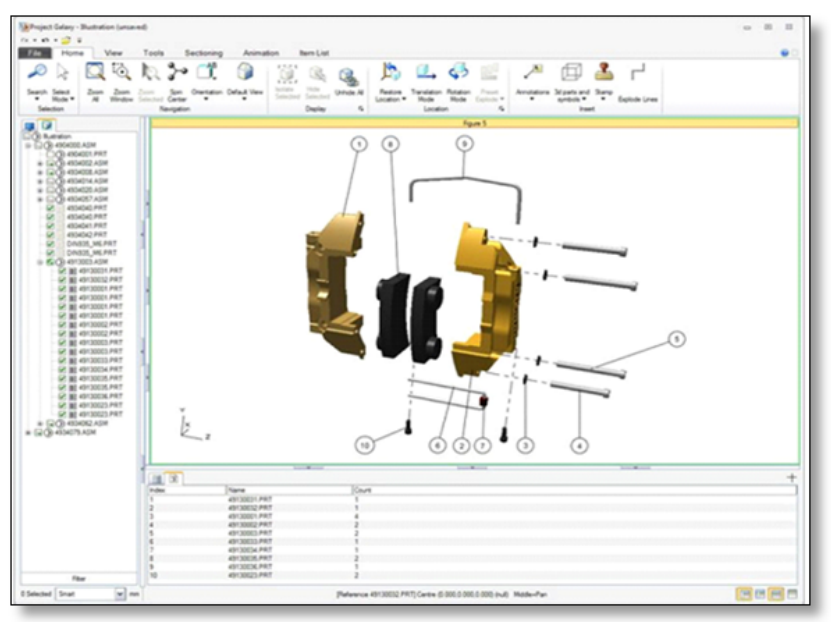

Figure 5. Environment Creo Illustrate [9]
This module allows us to design various animations of individual components of the assembly. We can move objects, reposition them or add various effects. These adjustments can be created at each step of the animation separately using all available components, or with the whole assembly. The sequences of this assembly should be designed so that it is possible to disassemble the mechanism. Coordination systems and other parameters are assigned to the individual components of the assembly, through which the future movements in directions of the distribution of the components are determined.

\subsection{Vuforia Studio}

Vuforia is a software platform for creating AR applications. Developers can add computer vision capabilities to any application, allowing them to recognize images, objects, and integrate into realworld space. Vuforia studio provides tools for the realization and creation of augmented reality content. It is easy-to-use software whose main goal is to transform digital information into the real world.

To present the augmented reality experience, a traditional 2D drawing documentation was created containing an assembly drawing and a drawing of the part on which the ThingMark 2D code was placed [5].
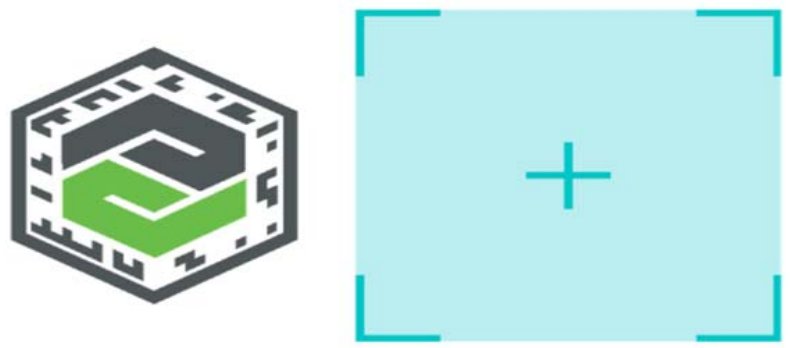

Figure 6. From the left ThingMark, Spatial Target

ThingMark is a flat graphic mark similar to a QR code, after which the relevant software, e.g. ThigWorx View draws a predefined model in space. The circumferential mark hides all the information associated with the application of the selected assembly. A unique code for each drawing ensures that the correct model is loaded from the database.

In addition to ThingMark, it is possible to use the Spatial Target function. With this selection, the chosen model is drawn on a pre-recognized flat surface (ground, table, and etc.), without the need for future use of any graphic mark, with the same coordinates as in the virtual environment of Creo software. A significant disadvantage of its application is that the desired model in the real environment can be drawn at different distances, which can lead to the overlapping of the drawing 
documentation. By using a graphic mark, we guarantee the exact position of the required components within the user's field of view, for example, so that the model, as well as the drawing documentation, is visible.

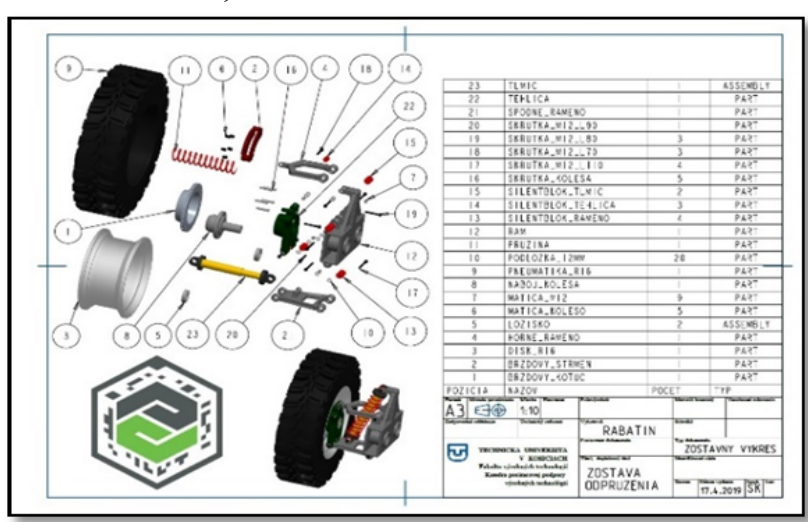

Figure 7. Assembly drawing supplemented by ThingMark

For easy and fast loading of the application, ThingMark was also imported into the assembly drawing, which is used to display 3D data in the real world. To finalize the settings, one has to select a unique ThingMark code in the Experiences section. Adequate visualization of the created scene in the environment of augmented reality is possible thanks to the correct recognition of the marker and definition of the initial position of the designed 3D model in space.

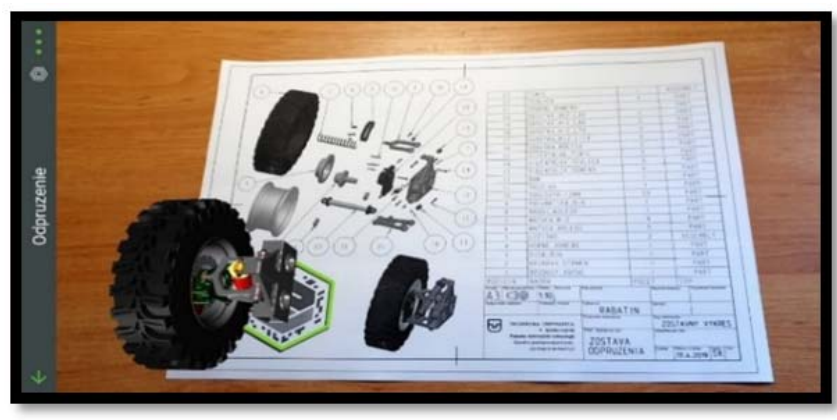

Figure 8. Enriched view of the drawing through the tablet screen

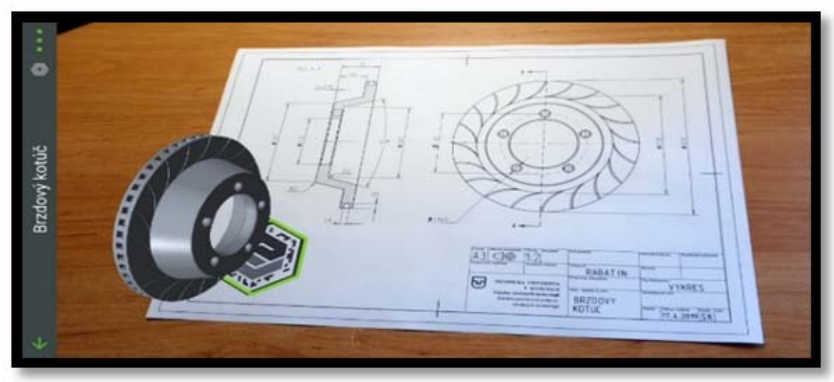

Figure 9. Brake disc visualization

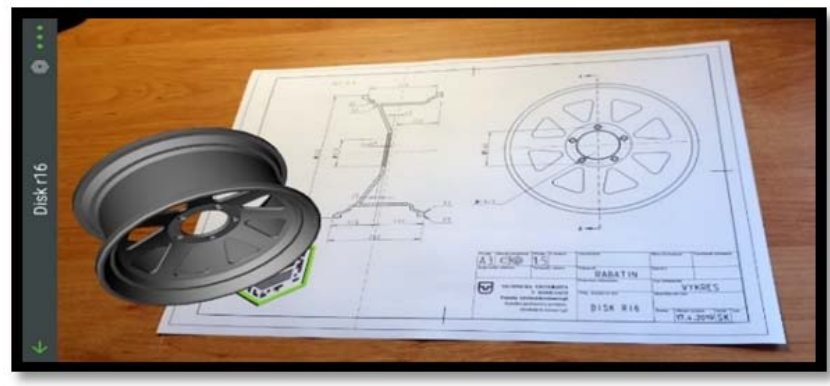

Figure 10. Wheel disk visualization

\section{Conclusion}

Augmented reality is a comprehensively evolving technology that has now found application and is occupying an increasing part of the educational process. This paper aimed to create and import a simple transmission mechanism into the physical world using augmented reality technology. The result of the paper is the possibility to investigate the individual components of the mechanism. In this way, students can see in detail various details of wheels, bearings, shafts, and the like. The advantage of introducing augmented reality into education is the introduction of a completely new dimension for the study of objects. This means that students are actively involved in the issue, whereby exploring the links of the set and the graphical possibilities of the application; they gather new knowledge and voluntarily / unconsciously educate themselves to a greater extent. Visualization of subjects allows students not only to memorize graphic diagrams but also easier to understand the connections between individual parts and thus can memorize the curriculum more easily or propose new solutions. Students are also more active in lectures and work with teachers.

\section{Acknowledgements}

This article was supported by the Ministry of education of Slovak Republic for supporting this research by the grant KEGA 004TUKE-4/2020. 


\section{References}

[1]. Havard, V., Jeanne, B., Lacomblez, M., \& Baudry, D. (2019). Digital twin and virtual reality: a cosimulation environment for design and assessment of industrial workstations. Production \& Manufacturing Research, 7(1), 472-489.

[2]. Ong, S. K., \& Nee, A. Y. C. (2013). Virtual and augmented reality applications in manufacturing. Springer Science \& Business Media.

[3]. Ribo, M., Pinz, A., \& Fuhrmann, A. L. (2001, May). A new optical tracking system for virtual and augmented reality applications. In IMTC 2001. Proceedings of the 18th IEEE Instrumentation and Measurement Technology Conference. Rediscovering Measurement in the Age of Informatics (Cat. No. 01CH 37188) (Vol. 3, pp. 1932-1936). IEEE.

[4]. Novak-Marcincin, J., Brazda, P., Janak, M., \& Kocisko, M. (2011). Application of virtual reality technology in simulation of automated workplaces. Tehnički vjesnik, 18(4), 577-580.

[5]. Production brief, ThingWorx Studio. Retrieved from: https://www.ptc.com/en/resources/iiot/productbrief/thingworx-platform [accessed: 19 January 2021].
[6]. Novák-Marcinčin, J., Barna, J., Janák, M., Fečová, V., \& Nováková-Marcinčinová, L. U. (2012, February). Composite lay-up process with application of elements of augmented reality. In The Engineering Reality of Virtual Reality 2012 (Vol. 8289, p. 82890P). International Society for Optics and Photonics.

[7]. Novak-Marcincin, J., \& Novakova-Marcincinova, L. (2013). Application of augmented reality technologies in virtual manufacturing. Academic Journal of Manufacturing Engineering, 11(4), 48.

[8]. Zhang, K. (2007). From abstract painting to information visualization. IEEE Computer Graphics and Applications, 27(3), 12-16.

[9]. PTC Augmented Reality Use Cases, Availible from: https://www.ptc.com/en/success-paths/develop-firstvuforia-studio-experience/plan/define-youraugmented-reality-use-case [accessed: 10 January 2021].

[10]. Barna, J., Fecova, V., Novak-Marcincin, J., \& Torok, J. (2012). Utilization of open source application in area of augmented reality assembling processes. Manufacturing Technology, 12(12), 2-7.

[11]. Jamali, S. S., Shiratuddin, M. F., \& Wong, K. W. (2013). A review of augmented reality (AR) and mobile-augmented reality (mAR) technology: Learning in tertiary education. Learning in Higher Education, 20(2), 37-54. 